\title{
Erratum to: An infant with hypercalcemia and rachitic changes: Answer
}

\author{
Khurrum Siddique • Ashley Lucke • Dolly Lucio • \\ Ximena Lopez • Mouin Seikaly
}

Published online: 13 September 2012

(C) IPNA 2012

Erratum to: Pediatr Nephrol

DOI 10.1007/s00467-012-2202-0

There was an error in author sequence.

The correct order is: Khurrum Siddique, Ashley Lucke, Dolly Lucio, Ximena Lopez, Mouin Seikaly

The online version of the original article can be found at http://dx.doi.org/ 10.1007/s00467-012-2202-0.

K. Siddique $\cdot$ D. Lucio $\cdot$ X. Lopez $\cdot$ M. Seikaly

Pediatric Nephrology, UT Southwestern Medical Center,

5323 Harry Hines Blvd,

Dallas, TX 75390, USA

A. Lucke $\cdot$ X. Lopez $\cdot$ M. Seikaly $(\bowtie)$

Childrens Medical Center of Dallas,

1935 Medical District Dr,

Dallas, TX 75235, USA

e-mail: mouin.seikaly@childrens.com 